\title{
THE
}

2014

\section{Who Benefits from Environmental Regulation? Evidence from the Clean Air Act Amendments}

Antonio Bento

Matthew Freedman

Corey Lang

University of Rhode Island, clang@uri.edu

Follow this and additional works at: https://digitalcommons.uri.edu/enre_facpubs

Part of the Agricultural and Resource Economics Commons

The University of Rhode Island Faculty have made this article openly available.

Please let us know how Open Access to this research benefits you.

This is a pre-publication author manuscript of the final, published article.

Terms of Use

This article is made available under the terms and conditions applicable towards Open Access Policy Articles, as set forth in our Terms of Use.

\section{Citation/Publisher Attribution}

Bento, A., Freedman, M., \& Lang, C. (2014). Who Benefits from Environmental Regulation? Evidence from the Clean Air Act Amendments. Review of Economics and Statistics, 97(3), 610-622.

Available at: http://dx.doi.org/10.1162/REST_a_00493

This Article is brought to you for free and open access by the Environmental and Natural Resource Economics at DigitalCommons@URI. It has been accepted for inclusion in Environmental and Natural Resource Economics Faculty Publications by an authorized administrator of DigitalCommons@URI. For more information, please contact digitalcommons-group@uri.edu. 


\title{
Who Benefits from Environmental Regulation? Evidence from the Clean Air Act Amendments
}

\author{
Antonio Bento, Matthew Freedman, and Corey Lang*
}

September 2014

\begin{abstract}
Using geographically disaggregated data and exploiting an instrumental variable strategy, we show that, contrary to conventional wisdom, the benefits of the 1990 Clean Air Act Amendments (CAAA) were progressive. The CAAA created incentives for local regulators to target the initially dirtiest areas for cleanup, creating heterogeneity in the incidence of air quality improvements that favored lower-income households. Based on house price appreciation, households in the lowest quintile of the income distribution received annual benefits from the program equal to $0.3 \%$ of their income on average during the $1990 \mathrm{~s}$, over twice as much as those in the highest quintile.
\end{abstract}

Keywords: Distributional Impacts, Hedonics, Housing Markets, Clean Air Act

JEL Classification Codes: H23, Q51, Q52, Q58, L51, R38

\footnotetext{
* Bento: Cornell University and NBER, 218 Warren Hall, Ithaca, NY 14853 (e-mail: amb396@cornell.edu). Freedman: Drexel University, 3220 Market St., Philadelphia, PA 19104 (e-mail: matthew.freedman@drexel.edu). Lang: University of Rhode Island, 214 Coastal Institute, Kingston, RI 02881 (e-mail: clang@mail.uri.edu). We would like to thank Gabriel Ahlfeldt, Michael Anderson, Maximillian Auffhammer, Justin Gallagher, Daniel Kaffine, Nicolai Kuminoff, David Lee, Kevin Roth, Nick Sanders, Reed Walker, Andrew Waxman, and Joshua Graff Zivin as well as seminar participants at the 2013 AERE session at the ASSA Meetings, the $1^{\text {st }}$ Northeast Workshop on Energy Policy and Environmental Economics, the Urban Economics Association Meetings, Case Western University, Cornell University, Drexel University, Resources for the Future, and the University of Michigan for helpful comments. We would also like to thank Joel Landry for research assistance. Lang acknowledges financial support from the Rhode Island Agricultural Experiment Station (contribution \#5401).
} 


\section{Introduction}

Conventional wisdom holds that environmental policies are regressive (Fullerton 2011, Banzhaf 2011, Bento 2013). This is in part because the costs of these policies tend to fall disproportionately on lower income households, who generally spend a higher fraction of their income on energy-intensive goods and are employed in larger numbers in energy-related industries. There is also some evidence that the benefits of environmental policies tend to accrue mainly to higher income households. Higher income households are more likely to be homeowners, and thus are more likely to reap the benefits of any capitalization of environmental improvements into property values.

The purpose of this paper is to carefully explore the distribution of the benefits of the 1990 Clean Air Act Amendments (CAAA), an important component in understanding the overall distributional impacts of the program. First enacted in 1970, the Clean Air Act established standards for the ambient concentrations of criteria pollutants with the goal of improving air quality and protecting human health. Following amendments in 1990, the Clean Air Act began regulating particulates less than 10 micrometers in diameter $\left(\mathrm{PM}_{10}\right)$, for which the negative health effects were deemed particularly severe. A county is designated to be out of attainment with the standard if at least one of the monitors within the county had concentrations of $\mathrm{PM}_{10}$ exceeding the standard.

Despite being the most ambitious federal environmental legislation to date, the existing literature provides little evidence on the extent to which the benefits in air quality improvements induced by the Clean Air Act and its amendments accrued to different segments of the population. Several studies that have attempted to measure the distribution of the benefits of the program have used locational equilibrium models and focused on a limited number of metropolitan areas, 
emphasizing within-metropolitan areas differences in the distribution of benefits that result from general equilibrium adjustments in housing prices (Sieg et al. 2004, Tra 2010). Other studies have examined the aggregate impacts on certain subgroups of the population, such as renters and homeowners (Grainger 2012), but have not accounted for important differences in the impacts of the program across households within these subgroups.

We provide new, compelling evidence that the benefits of the 1990 CAAA, measured by capitalization of air quality improvements in housing prices and rents, were in fact progressive, contrary to what these past studies suggest. First, we demonstrate that the air quality improvements induced by the 1990 CAAA were highly localized, as local regulators had incentives to target the areas around non-attainment monitors as a strategy to ensure their counties were in attainment with federal standards. Second, we estimate capitalization of the air quality changes induced by the program. For homes located within five miles of a non-attainment monitor, which we show to be owned by relatively low-income households on average, our estimate of the elasticity of house prices with respect to $\mathrm{PM}_{10}$ reductions is about -0.6 . For homes located further away, which tend to be owned by more affluent households, we detect sharply less appreciation attributable to the 1990 CAAA. Rental prices also appear to have increased in a localized fashion, but the capitalization of air quality improvements into rents is substantially smaller and less consistent than for housing prices.

Consequently, lower income homeowners tended to enjoy the greatest benefits from the 1990 CAAA, as these were the homeowners located in areas that experienced the largest improvements in air quality. Based on house price appreciation, households in the lowest quintile of the income distribution received annual benefits from the program equal to $0.3 \%$ of their income on average during the 1990s, over twice as much as those in the highest quintile. Importantly, though, while 
poorer households living close to monitors benefited greatly from the reductions in pollution induced by the 1990 CAAA, a larger number of households living further from monitors also benefited, but each to a smaller extent.

Our main empirical challenge is to estimate the causal effect of declines in $\mathrm{PM}_{10}$ on housing prices. To do this, we assemble a unique dataset and exploit a quasi-experimental research design. The key components of the data are monitor-level readings of $\mathrm{PM}_{10}$ concentrations and tract-level census data on housing prices, rents, and socio-economic characteristics. Combining these data with attainment designations, we follow Chay and Greenstone (2005) in implementing an instrumental variable (IV) approach to overcome biases from confounding factors that are simultaneously correlated with pollution and housing prices. In Chay and Greenstone's (2005) work, which is conducted at the county level, county attainment designations under the 1970 Clean Air Act serve as an instrument for changes in pollution over the decade. Our empirical strategy differs in three important ways from that of Chay and Greenstone (2005). First, motivated by both the degree of observed heterogeneity in demographic characteristics of households as well as observed variation in air quality improvements within counties, we conduct our analysis of the CAAA in the 1990s at the monitor level as opposed to the county level. Second, we rely on both monitor and county attainment designations as instruments for changes in $\mathrm{PM}_{10}$. We use monitor attainment designations as an instrument because it better matches the behavior of local regulators and is a good predictor for the spatial variation in the drops of $\mathrm{PM}_{10}$ within non-attainment counties with multiple monitors. Finally, instead of a simple binary instrument that only captures attainment status, we use a more sophisticated instrument that reflects the persistence of non-attainment status to capture differential responses depending on the severity of violations. Our spatially disaggregated approach exploiting the behavior of local regulators allows us to uncover the 
incidence of the program in a more comprehensive way than past studies, and provides new estimates highlighting how the program's benefits were progressively distributed, with lower income households experiencing larger welfare gains on average than higher income households.

The rest of the paper is organized as follows. The next section provides an overview of air quality regulation and describes local regulator behavior in response to the CAAA. Section III discusses the data we use in this study and provides some descriptive statistics. We describe our identification strategy and detail our empirical model in Section IV, then present our results along with robustness tests in Section V. We discuss the implications of our findings for understanding the progressivity or regressivity of environmental policies in Section VI. Section VII concludes.

\section{Environmental Regulation and the Clean Air Act Amendments}

\section{A. Particulate Matter Regulation under the CAAA}

Particulate matter (PM) is a term used for a class of solid and liquid air pollutants. PM originates from a variety of mobile and stationary sources, including motor vehicles, construction sites, and power plants. With the 1970 Clean Air Act, which was an extension of the original 1963 Clean Air Act, the EPA was authorized to enforce a National Ambient Air Quality Standard (NAAQS) for total suspended particulates (TSPs), which include PM less than 100 micrometers

in diameter. A nationwide network of air pollution monitors allowed the EPA to track TSPs, and two types of standards were used to determine whether pollution levels were sufficiently dangerous to warrant regulatory action. As the U.S. EPA (2005) states, "primary standards set limits to protect public health, including the health of 'sensitive' populations such as asthmatics, children, and the elderly. Secondary standards set limits to protect public welfare, including protection against 
decreased visibility, damage to animals, crops, vegetation, and buildings." For each standard, the EPA considered both a 24-hour average and an annual average.

In addition to adding provisions for regulating ozone depletion, addressing acid rain, and establishing new auto gasoline reformulation requirements, the amendments to the Clean Air Act passed in 1990 began regulating particulates less than ten micrometers in diameter $\left(\mathrm{PM}_{10}\right)$, for which the negative health effects were deemed particularly severe. While particulates larger than ten micrometers in diameter can generally be filtered in the nose and throat, those less than ten micrometers in diameter cannot and may cause health problems if sufficient quantities settle in the bronchi and lungs. The primary standard under the 1990 CAAA required that the three-year geometric average of $\mathrm{PM}_{10}$ concentration for each monitor in a county be less than $50 \mu \mathrm{g} / \mathrm{m}^{3}$. It further required via a secondary standard that the 24-hour average concentrations at a monitor not exceed $150 \mu \mathrm{g} / \mathrm{m}^{3}$.

If any monitor within a county exceeds these standards, the EPA can designate the county "non-attainment." As part of a state implementation plan (SIP), a non-attainment county is required outline its strategy to reduce air pollution levels in order to be compliant with the NAAQS. If pollution levels continue to exceed the standards or if a county fails to abide by an approved plan, the EPA can impose sanctions on the county in violation. These sanctions may include the withholding of federal highway funds and the imposition of technological "emission offset requirements" on new or modified sources of emissions within the county (National Archives and Records Administration 2005).

\section{B. Local Regulator Behavior}

For a county to be deemed out of attainment, pollution readings from only one monitor within that county need to exceed the primary or secondary standards. As such, in counties with more 
than one monitor, local regulators are likely to allocate a disproportionate amount of their effort toward reducing $\mathrm{PM}_{10}$ levels around monitors with pollution readings near or above the federal thresholds, as these monitors put the county as a whole at risk of falling out of attainment. ${ }^{1}$

Auffhammer et al. (2009) provide evidence of strategic behavior among local regulators. They show that the average drop in $\mathrm{PM}_{10}$ near non-attainment monitors located in non-attainment counties relative to attainment monitors in non-attainment counties was a sizable $5.43 \mu \mathrm{g} / \mathrm{m}^{3}$ per year. They interpret their results as evidence that regulators target non-attainment monitors for more aggressive action, and thereby minimize future expected costs for the county as a whole. Additional discussions with EPA and South Coast Air Quality Management District officials confirm such behavior. At the local level, policymakers have various ways to enforce the regulations either directly through the CAAA or indirectly through related policies that will tend to result in uneven reductions in air pollution across space. ${ }^{2}$ In this paper, we leverage spatial heterogeneity in monitoring and enforcement efforts within counties to measure the distribution of the benefits of the 1990 CAAA.

\section{Data and Descriptive Statistics}

This section briefly discusses the sources and relevant features of the air quality, regulatory, and housing and population datasets we use in the analysis. We refer the reader to the online appendix for additional details about the data.

\footnotetext{
${ }^{1}$ It is also well documented in the epidemiological literature that the relationship between mortality and particular matter is non-linear. Dockery et al. (1993) estimate convex damage functions, providing further rationale for prioritizing particularly dirty areas for cleanup.

${ }^{2}$ For example, officials may step up inspections and enforcement at polluting facilities in dirty areas. Plants may be required to install equipment to reduce PM and officials may use permitting rules to ensure that facilities meet guidelines for regulated emissions. Construction sites and dirt roads may also be kept wet to limit dust. Additionally, some areas impose direct regulations on the oxygenated content of fuels, more stringent zoning regulations that make it harder for polluting facilities to locate in these areas, traffic alleviating policies and smart growth strategies to reduce emissions from transportation, and paving of side roads.
} 


\section{A. Air Quality Data}

The $\mathrm{PM}_{10}$ concentrations were obtained from the Air Quality Standards (AQS) database, which is maintained by the EPA. For each monitor, the database includes the annual mean concentrations, the highest concentration recorded in any 24-hour period, the geospatial coordinates of the monitor, and several reliability measures. For the purposes of our analysis, we restrict attention to monitors with reliable readings. ${ }^{3}$ Further, we require that monitors have at least one reliable reading in each of the following sets of years: 1989-1990, 1991-1996, and 1999-2000. This enables us to match concentration levels with decennial census data and construct instruments from middecade observations. ${ }^{4}$ The reliability and timing requirements place significant demands on the set of monitors, and as a result, our final sample consists of 375 monitors located in 230 counties. While only a small fraction of counties in the U.S., these 230 counties are located in densely populated areas and contain approximately one-third of the total U.S. population. ${ }^{5}$ Observed changes in pollution in our sample are also consistent with recent work using a broader sample of monitors. Based on our sample, the average concentrations of $\mathrm{PM}_{10}$ declined by $19 \%$ in the $1990 \mathrm{~s}$, which is consistent with the findings of Auffhammer et al. (2009), who rely on a much larger sample of monitors.

We obtained the county attainment designations from the annual code of federal regulations (CFR). While the EPA designates each county in the U.S. as attainment or non-attainment, not all counties contain air quality monitors that meet the time and reliability requirements necessary to

\footnotetext{
${ }^{3}$ See the online appendix for more details on the requirements for reliability.

${ }^{4}$ If a monitor has a valid observation from 1990 (2000), then that observation is attached to the 1990 (2000) census data. If a monitor does not have a valid observation from 1990 (2000), but does from 1989 (1999), then the 1989 (1999) observation is attached to the 1990 (2000) census data.

${ }^{5}$ Figure A1 in the online appendix shows the geographic distribution of the 375 monitors that are included in our sample. Table A1 in the online appendix shows that $1990 \mathrm{PM}_{10}$ levels are higher on average for included monitors relative to the broader population of monitors. However, the decadal changes are insignificantly different across each group. Further, in robustness tests, we relax the monitor reliability requirements.
} 
be included in our sample. ${ }^{6}$ For the purpose of our analysis, we also assign attainment status to each monitor for each year using the EPA's rules. If in year $t$ a monitor's annual $\mathrm{PM}_{10}$ concentration is greater than $50 \mu \mathrm{g} / \mathrm{m}^{3}$ or its 24 -hour concentration exceeds $150 \mu \mathrm{g} / \mathrm{m}^{3}$ more than once, then that monitor is designated non-attainment in year $t+1$.

\section{B. Demographic and Housing Characteristics}

The demographic and housing data come from the GeoLytics Neighborhood Change Database. This dataset aggregates decennial census microdata to normalized tract boundaries such that the data are directly comparable across time periods. For the years 1990 and 2000, we obtained tractlevel data for the median owner-occupied housing value, median rental rate, housing characteristics, and socioeconomic characteristics. A complete list of these variables appears in Table A2 in the online appendix. ${ }^{7}$

Using mapping software, we matched each monitor to a single census tract. We then calculated the distance between each tract in the data and the closest tract containing a monitor. For the purposes of our empirical analysis, we construct concentric ring buffers around each monitor at distances of $0-1,1-3,3-5,5-10$, and 10-20 miles. The rings are constructed such that county lines and lines equidistant with other monitors in the same county truncate the rings. The number of tracts, or partial tracts, included in a ring initially increases with distance, but then declines, reflecting the facts that tracts are larger in rural areas and that at larger radii, rings bump into county lines and lines equidistant with other monitors. ${ }^{8}$ Following Greenstone and Gallagher (2008) and

\footnotetext{
${ }^{6}$ Figure A2 in the online appendix displays the 1990 attainment status for each county in our sample. The spatial distribution of non-attainment counties confirms widely held beliefs of which areas are most polluted. The southwestern U.S. (particularly Los Angeles), mountain cities like Denver and Salt Lake, and rust belt cities (Chicago, Detroit, Cleveland, and Pittsburgh) are all in the non-attainment group. While some counties are persistently nonattainment through the 1990s, individual monitors show much more variation.

${ }^{7}$ We omit tracts that have missing values for the variables of interest or report anomalous house price changes; for further details, see the online appendix.

${ }^{8}$ We illustrate the construction of the rings for the Chicago metro area in Figure A3 in the online appendix.
} 
Banzhaf and Walsh (2008), we aggregate housing and socioeconomic data for all tracts falling within a given ring, using weights equal to each tract's land area within the relevant ring multiplied by its population. ${ }^{9}$ Cumulatively, the rings cover $92 \%$ of total county population (see Table A3 in the online appendix).

\section{Descriptive Statistics}

Figure 1 shows $\mathrm{PM}_{10}$ reductions between 1990 and 2000 for monitors in attainment located in counties in attainment, for monitors in attainment located in counties out of attainment, and for monitors out of attainment. ${ }^{10}$ The decline in concentrations for in-attainment monitors located in attainment and non-attainment counties is $5.1 \mu \mathrm{g} / \mathrm{m}^{3}$ and $7.0 \mu \mathrm{g} / \mathrm{m}^{3}$, respectively. The out-ofattainment monitor group experiences substantially larger declines in concentrations over the decade, $15.4 \mu \mathrm{g} / \mathrm{m}^{3}$ on average. This pattern highlights the substantial within-county variation in pollution driven by the CAAA and its attainment designations. As we would expect, and as Auffhammer et al. (2009) also show, $\mathrm{PM}_{10}$ reductions are localized and center around monitors responsible for inciting regulatory action. That the EPA's non-attainment designations were generally effective in reducing pollution levels is consistent with past work documenting the enforcement of air quality standards under the 1990 CAAA (Henderson 1996, Nadeau 1997, Becker and Henderson 2000). We further explore the spatial scale of pollution reductions associated with non-attainment designations in the empirical analysis. ${ }^{11}$

\footnotetext{
${ }^{9}$ When tracts are aggregated to a ring level, median house value and median family income lose their "median" nature, but instead are weighted averages of medians.

${ }^{10}$ A monitor is classified as non-attainment if it exceeds either of the EPA standards at some point during 19921997. A monitor is classified as county non-attainment if it is located in a county that is non-attainment at some point during 1992-1997, but is not non-attainment itself. All but one monitor designated as non-attainment are located in non-attainment counties.

${ }^{11}$ In a series of tests, we examined how pollution levels and changes in pollution across monitors varied with distance between monitors. In Table A4 in the online appendix, we find a strong positive correlation between $\mathrm{PM}_{10}$ levels in 1990 that diminishes only slightly as we move away from the monitors; however, it is still strong and positive for monitors even 50 miles apart. More important for our empirical analysis, the correlation in changes in pollution between 1990 and 2000 fades more quickly with distance, with the correlation falling from close to 0.7 for monitors
} 
Table 1 breaks out demographic and housing characteristics, including 1990 levels as well as changes between 1990 and 2000, for tracts with monitors in attainment in counties that are in attainment, monitors in attainment that are in counties out of attainment, and monitors that are out of attainment. Consistent with Figure 1, the first row shows that monitors out of attainment had higher $\mathrm{PM}_{10}$ levels in 1990 as well as greater reductions in $\mathrm{PM}_{10}$ between 1990 and 2000. It also shows that the initially dirtiest areas near non-attainment monitors typically had lower initial house values and income levels as well as higher shares of minorities and unemployment rates.

Figure 2 plots non-parametric relationships between a tract's distance to the closest air quality monitor in our sample and selected demographic and housing characteristics of that tract, including median housing price, median rent, share of housing units owner occupied, median family income, population density, share college educated, share white, and the unemployment rate in 1990. Figure 2 highlights systematic variation across space for each socioeconomic variable; as the distance from a monitor increases, median housing and rental values, the share of units owner occupied, median incomes, share college educated, and share white all increase, whereas population density and unemployment rates decrease. Figure 2 underscores the fact that the monitors are placed in tracts that are systematically different than other tracts and the county as a whole. This is a direct consequence of the EPA's requirement that monitors be located in densely populated areas. ${ }^{12}$ We exploit how demographic and housing characteristics vary as a function of distance to the closest monitor in the empirical analysis to help identify the distribution of benefits of the pollution reductions induced by the 1990 CAAA.

within one mile of one another to around 0.40 for monitors 20-40 miles apart. The precise correlation depends on which monitors we include in the sample and what time period we consider, but the pattern is the same regardless.

${ }^{12} \mathrm{See}$ http://epa.gov/airquality/montring.html\#montypes. Plots for 2000 characteristics are similar to those for 1990 , indicating that the characteristics of neighborhoods close to and further from monitors are fairly stable over time. 


\section{Empirical Approach}

In this section, we outline our econometric approach to estimating the implicit value of air quality derived from housing market data. We rely on the hedonic model developed by Rosen (1974), which characterizes a market for heterogeneous goods and allows one to assign prices to the attributes of those goods. We estimate regressions using spatially disaggregated data in order to examine how the capitalization of air quality improvements varies across space, which, as discussed in the previous section, has important implications for the incidence of the 1990 CAAA.

Our analysis takes place at the monitor level, with demographic and housing information based on rings of different radii around each monitor. We separately estimate our models for owneroccupied house values and for rents; given a large fraction of renters are low-income households, determining the impact of air quality changes induced by the 1990 CAAA on rents is important in evaluating its overall distributional consequences.

Our basic specification is

$$
\Delta p_{i}=\theta \Delta P M_{i}+\Delta \mathbf{X}_{i} \boldsymbol{\beta}+\varepsilon_{i},
$$

where $p_{i}$ is the natural $\log$ of either median owner-occupied housing value or median rent in area $i, P M_{i}$ is the concentration of $\mathrm{PM}_{10}$ in area $i$, and $\mathbf{X}_{i}$ is a vector of area $i$ 's housing and neighborhood characteristics. ${ }^{13}$ In equation (1), prices, $\mathrm{PM}_{10}$ concentrations, and the vector of controls are

\footnotetext{
${ }^{13}$ The matrix $\mathbf{X}$ includes the following variables, all differenced between 2000 and 1990: total housing units, percent of housing units occupied, percent of housing units owner occupied, percent of housing units heated by coal, percent of housing units heated by wood, percent of housing units without a kitchen, percent of housing units with full plumbing, percent of owner-occupied units with two bedrooms, percent of owner-occupied units with three bedrooms, percent of owner-occupied units with four bedrooms, percent of owner-occupied units with five or more bedrooms, percent of owner-occupied units that are single detached units, percent of owner-occupied units that are single attached units, percent of owner-occupied units that are mobile homes, percent of owner-occupied units that were built 5-10 years ago, percent of owner-occupied units that were built 10-20 years ago, percent of owner-occupied units that were built 20-30 years ago, percent of owner-occupied units that were built 30-40 years ago, percent of owner-occupied units that were built 40-50 years ago, percent of owner-occupied units that were built 50 or more years ago, percent of renter-occupied units with two bedrooms, percent of renter-occupied units with three bedrooms, percent of renteroccupied units with four bedrooms, percent of renter-occupied units with five or more bedrooms, percent of renteroccupied units that are single detached units, percent of renter-occupied units that are single attached units, percent of
} 
differenced between 2000 and 1990. This first-difference approach controls for both observable and unobservable time invariant characteristics of areas that might be correlated with house prices and air quality, such as climate and topographical features, transportation infrastructure, and population density. In this time differenced specification, $\theta$ measures capitalization.

As Table 1 suggests, monitor non-attainment areas differ along several observable dimensions from monitor in-attainment areas, irrespective of whether the non-attainment monitors are in nonattainment counties or not. In particular, monitor non-attainment areas have relatively low house prices, low median incomes, low shares of residents that are white, high unemployment rates, and low shares of houses with three or more bedrooms. ${ }^{14}$ To the extent that these characteristics are time-invariant, a differencing approach will sweep out these effects. However, changes in unmeasured characteristics of locations that are correlated with $\mathrm{PM}_{10}$ and also independently affect $p$ might still bias estimates of $\theta$. For example, expansions in local transportation infrastructure or increases in overall economic activity could affect both pollution levels and housing prices. We would generally expect such correlations to bias the coefficient on pollution toward zero.

We exploit the 1990 CAAA and its implications for local regulator behavior to address the simultaneity that would otherwise exist between house prices and pollution. Our identification

renter-occupied units that are mobile homes, percent of renter-occupied units that were built 5-10 years ago, percent of renter-occupied units that were built 10-20 years ago, percent of renter-occupied units that were built 20-30 years ago, percent of renter-occupied units that were built 30-40 years ago, percent of renter-occupied units that were built 40-50 years ago, percent of renter-occupied units that were built 50 or more years ago, median family income, percent of residents with less than a high school degree, percent of residents with a college degree, percent of residents who are Black, percent of residents who are Latino, percent of residents under the age of five, percent of residents over the age of 65 , percent of residents that are foreign born, percent of households that are headed by a female, percent of residents that live in the same house as five years ago, percent of residents that are unemployed, percent of residents that are employed in manufacturing, percent of residents that are below the poverty line, percent of residents that receive public assistance, population density, and local home price indices. Sample means for these variables at the tract level are provided in Table A2 in the online appendix.

${ }^{14}$ With regard to the changes between 1990 and 2000 reported in Table 1, changes in $\mathrm{PM}_{10}$ conform to our expectations, but surprisingly, changes in median house values do not. While aggregate data at the county level show that house prices appreciated more in non-attainment counties, house prices at the tract level do not appreciate in line with changes in $\mathrm{PM}_{10}$. This lack of correlation highlights the importance of including other covariates that affect house values in our specification. 
strategy builds on that of Chay and Greenstone (2005), who instrument for changes in pollution at the county level between 1970 and 1980 using county non-attainment status in the mid-1970s. However, following more recent work examining the more localized externalities associated with environmental improvements (e.g., Gamper-Rabindran et al. 2011), we exploit heterogeneity within counties in pollution levels and socio-economic characteristics as well as in officials' behavior. Figure 1 highlights the substantial degree of within-county variation in pollution reductions, which is in part driven by local regulator efforts to bring dirtier monitors in line with the EPA's standards. Our IV strategy therefore uses monitor attainment status as an instrument for localized pollution reductions. ${ }^{15} \mathrm{We}$ also consider overidentified models that use both monitor attainment status and county attainment status as instruments. Further, to capture heterogeneity in the persistence of non-attainment and its potentially differential impact on the extent of air quality improvements, our instruments are constructed as ratios of years out of attainment. Specifically, our monitor (county) instrument is the ratio of years that the monitor (county) is out of attainment to the number of years for which there is a record during the time span 1992-1997. With the county instrument, the denominator is always six years; for the monitor instrument, due to some monitors not having valid data for all years, the denominator can vary from one to six years. ${ }^{16}$

The first-stage and reduced-form equations of the IV analysis can be written as

$$
\begin{array}{r}
\Delta P M_{i}=\varphi N_{i}+\Delta \mathbf{X}_{i} \boldsymbol{\Pi}+\mu_{i} \\
\Delta p_{i}=\gamma N_{i}+\Delta \mathbf{X}_{i} \Omega+v_{i},
\end{array}
$$

\footnotetext{
${ }^{15}$ Non-attainment could result from violation of either the annual standard or the 24-hour standard.

${ }^{16}$ While we include in our sample only monitors that have valid $\mathrm{PM}_{10}$ readings in both 1990 and 2000, our ratio instrument avoids further selection issues that might arise if we were to require monitors to have a reading one or more particular years during the 1990s. As discussed in Section V.D., the results are similar when we use alternative instruments as well as when we relax reliability requirements for monitors in the sample.
} 
where the instrument $N_{i}$ is equal to the ratio of non-attainment years during the time span 1992 to 1997. For $\theta_{I V}$ to be a consistent estimate of the effect of changes in $\mathrm{PM}_{10}$ on prices, it must be the case that non-attainment status affects changes in $\mathrm{PM}_{10}$ and that, conditional on other observable neighborhood and housing characteristics, non-attainment status only affects house prices through its impact on $\mathrm{PM}_{10} \cdot{ }^{17}$ As Figure 1 suggests, and as we show more rigorously in Section V.A., the first condition clearly holds. While we cannot conclusively show that the exclusion restriction holds, we include an extensive set of controls and conduct a battery of robustness tests aimed in part at mitigating concerns that any shocks to prices between 1990 and 2000 are not orthogonal to shocks to $\mathrm{PM}_{10} .^{18}$

We apply the reduction in pollution measured at the monitor level to each ring, although based on the reduced-form results presented below and the observed gradient in the magnitude of pollution changes, there is reason to believe that declines in pollution tend to be larger in closer rings than in further away rings. Given this, we would expect estimates of $\varphi$ in equation (2) to be upper bounds on the true reduction in pollution experienced in more distant rings. In turn, we would expect the IV estimates of $\theta$ in equation (1) to be biased downward in absolute value for the rings further away, meaning that the magnitude of the estimated effects could be larger than we find. ${ }^{19}$

\footnotetext{
${ }^{17}$ Regulatory action in response to non-attainment could affect other pollutants besides $\mathrm{PM}_{10}$, such as ozone. Changes in $\mathrm{PM}_{10}$ are more likely to be capitalized into housing markets given it is visible to the unaided human eye, unlike most other air pollutants.

${ }^{18}$ One concern would be if measures aimed at reducing pollution to achieve or maintain attainment (e.g., curtailing manufacturing activity) independently affect house prices. However, we believe that with our extensive set of covariates (including, for example, manufacturing employment), we effectively control for such possible channels.

${ }^{19}$ To the extent that people were cognizant of possible increases in the stringency of pollution control measures prior to 1990 and anticipated future air quality improvements in their local areas, we might expect prices to have capitalized those improvements by 1990. While we do not believe that the general public was aware of attainment status and likely future changes in air quality owing to the 1990 CAAA, if there were some capitalization of anticipated pollution reductions by 1990 , it would lead us to underestimate the impact of the 1990 CAAA.
} 
One concern is that if house price trends across regions are correlated with patterns of air quality improvements, it could bias our estimates of the effects of pollution reductions on home values. To address this issue, we include as a control local home price indices from Freddie Mac, and specifically the conventional mortgage home price index (CMHPI). We use MSA-level indices when available and state-level indices otherwise. ${ }^{20}$ In effect, our estimates reflect the effects of changes in $\mathrm{PM}_{10}$ on changes in prices beyond those that would be expected given regional price trends. In robustness tests, we also consider pre-treatment trends in neighborhood conditions to address concerns that neighborhoods in and out of attainment were on different initial trajectories.

\section{Results}

\section{A. First-Stage Results}

We begin with an analysis of the first-stage estimates of the relationship between nonattainment and air pollution reductions. The results for the 0-1 mile ring appear in Table 2. The first-stage is identical for owners and renters, as the regressions include the same controls. We show results from a just-identified model using the fraction of years between 1992 and 1997 that the monitor is out of attainment as an instrument (column (1)) as well as results from an overidentified model using both the fraction of years between 1992 and 1997 that a monitor is out of attainment as well as the fraction of years between 1992 and 1997 that a county is out of attainment (column (2)).

Consistent with the descriptive statistics in Table 1, the results in column (1) show that, relative to areas with monitors always in attainment, areas with monitors out of attainment experience an

\footnotetext{
${ }^{20}$ Results using home prices deflated by these local indices are very similar to our main estimates; these results are available upon request. As a robustness test (discussed in Section V.D), we also consider regressions with region fixed effects, which additionally control for any unobserved trend in home prices at the region level. The results are very similar to the main estimates.
} 
$11.9 \mu \mathrm{g} / \mathrm{m}^{3}$ decline in $\mathrm{PM}_{10}$. Given the mean value of the monitor-level instrument is 0.4 , the average monitor in the non-attainment group experiences a decline in $\mathrm{PM}_{10}$ of $4.7 \mu \mathrm{g} / \mathrm{m}^{3}$. The overidentified model in column (2) reveals that both monitor non-attainment and county nonattainment are associated with declines in $\mathrm{PM}_{10}$. Again echoing Table 1, the results imply that the largest drops in $\mathrm{PM}_{10}$ occur near non-attainment monitors that are located in counties out of attainment, while smaller drops occur near attainment monitors that are located in counties out of attainment. The coefficient estimates in the just-identified and overidentified models are highly significant, and with F-statistics of 19 and 15, respectively, the instruments appear to be highly relevant. $^{21}$

\section{B. Reduced-Form Results}

The reduced-form relationships between non-attainment status and changes in house prices and rents appear in Panel A of Tables 3 and 4. We show results for prices and rents within rings of 0-1 mile, 1-3 miles, 3-5 miles, 5-10 miles, and 10-20 miles around monitors, and present specifications with only the monitor instrument and specifications with both instruments.

For homeowners (Table 3), there is a striking pattern across rings in each model, with house price growth strongly positively related to non-attainment within close rings but increasingly less related to non-attainment in more distant rings around monitors. This is consistent with reductions in pollution that are confined to relatively small areas around non-attainment monitors. Indeed, based on the reduced-form estimates, it appears that declines in pollution near non-attainment monitors only occur within about five miles from the monitor. If the reductions in pollution were more evenly distributed over a wide area, we would expect to see a stronger relationship between non-attainment status of a monitor and house prices even in more distant rings around the monitor.

\footnotetext{
${ }^{21}$ The corresponding first-stage regressions for each ring beyond 1 mile appear in Table A5 in the online appendix. Results are very similar, but change slightly due to different values of the control variables.
} 
However, the results suggest that non-attainment status matters only for tighter rings around the monitor. $^{22}$

The reduced-form results for renters in Panel A of Table 4 show a different pattern than those for homeowners. With the exception of the 1-3 mile ring, where rents are positively related with non-attainment status, there appears to be very little relationship between non-attainment and rents.

\section{Second-Stage Results}

In Panel B of Tables 3 and 4, we present the second stage results from our IV analysis for homeowners and renters for each ring around monitors and for just-identified and overidentified models. ${ }^{23}$ We apply the reduction in pollution measured at the monitor level to each ring, although based on the reduced-form results, there is reason to believe that declines in pollution tend to be larger in smaller rings than in larger rings. Given this, we would expect estimates of $\varphi$ in equation (2) to be upper bounds on the true reduction in pollution experienced in more distant rings. In turn, we would expect the IV estimates of $\theta$ in equation (1) to be biased downward in absolute value for the larger rings.

Focusing on the homeowner results for the 0-1 ring around monitors and using the justidentified model (Table 3, column (1)), the IV estimates imply that a one unit decrease in PM 10 increases house prices by a statistically significant $0.92 \%$. The estimate in the overidentified model (column (2)) is similar at $1.33 \%$ (which is also statistically significant). The implied elasticity of house prices with respect to $\mathrm{PM}_{10}$ reductions is about -0.6 . This is roughly twice as large as Chay

\footnotetext{
${ }^{22}$ If it were the case that homeowners in more distant rings value air quality improvements less than homeowners close to monitors, the results could still be consistent with more evenly distributed pollution reductions. However, as Figure 2 shows, residents of more distant rings are on average much richer than those in closer rings, and past research suggests that if anything, richer homeowners value air quality improvements more than poorer homeowners (Fullerton 2011).

${ }^{23}$ For the interested reader, Table A6 in the online appendix presents cross-section and first-difference regression results.
} 
and Greenstone's (2005) estimate of the elasticity of house prices with respect to reductions in total suspended particulates (TSPs).

The IV estimates of the impacts of pollution reductions on house prices get smaller, albeit not statistically different from one another, as we consider larger rings of up to five miles around monitors. Using estimates from the just-identified model, the increase in home values on average in response to a one unit decline in $\mathrm{PM}_{10}$ measured at the monitor is $0.82 \%$ for houses $1-3$ miles from the monitor and $0.67 \%$ for houses 3-5 miles from the monitor. Echoing the reduced-form results, we do not detect any significant capitalization of air quality improvements in housing prices in the 5-10 mile ring or 10-20 mile ring.

Based on these results, we can calculate the implied marginal willingness-to-pay (MWTP), the annual dollar amount a household would pay to face one unit less of $\mathrm{PM}_{10}$. To convert house prices to annual expenditure, we assume an $8 \%$ interest rate and a 30 -year mortgage. ${ }^{24}$ The implied MWTP for a one-unit reduction in $\mathrm{PM}_{10}$ (in dollars) based on our preferred estimates are stable at around \$120-\$130 for rings within five miles of the monitor. This MWTP estimate is consistent with other estimates based on different data sets and identification strategies. For example, Bayer et al. (2009) find a MWTP of \$149 (\$1982-84) using decennial census data and an IV strategy based on long-range pollution transport. Bajari et al. (2012) use sales data from a single city and estimate a MWTP of \$94. Lang (2012) uses a panel of individual housing units and a similar identification strategy as this paper and finds a MWTP of \$212, suggesting aggregation bias is minimal.

Meanwhile, the results in Panel B of Table 4 suggest that, with the exception of the 1-3 mile ring, there is no discernible impact of changes in air pollution on rents. For the 1-3 mile ring, the

\footnotetext{
${ }^{24} \mathrm{We}$ choose $8 \%$ because it is roughly the average 30-year mortgage rate that prevailed during the $1990 \mathrm{~s}$.
} 
just-identified IV estimates imply that a one unit decrease in $\mathrm{PM}_{10}$ increases rents by a statistically significant $0.32 \%$. The implied elasticity of rents with respect to pollution reductions is -0.2 . Notably, for renters in the 1-3 mile ring, the implied MWTP is substantially lower than for homeowners at only $\$ 27$. These results imply that, for the 1-3 mile ring, capitalization of air quality improvements in rents is only $40 \%$ of that in housing prices. ${ }^{25}$

\section{Supporting Analysis}

We conducted a series of robustness checks and supplementary analyses, including specifications incorporating pre-1990 trends, analyses using different sets of monitors, regressions using alternative instrument definitions, and tests for sorting.

Robustness Checks - In Table 5, we show results for a number of other robustness tests for homeowners. ${ }^{26}$ First, we examine the extent to which pre-treatment trends in neighborhood conditions affect the results. To the extent that neighborhoods that experienced large reductions in pollution levels were already on an upward trajectory, we might attribute further improvements to changes in air quality, when in fact they might have occurred even in the absence of the 1990 CAAA and regulator efforts to reduce local pollution. In Panel A of Table 5, we show results in which we include as controls differences between 1980 and 1990 in log median income, share black, $\log$ population, and log housing units. ${ }^{27}$ We lose close to $20 \%$ of the observations due to missing data in 1980 , when the country was not fully tracted. Nonetheless, the results are remarkably similar with the inclusion of these pre-treatment trends; the IV estimates continue to

\footnotetext{
25 Though more disaggregated, our results are consistent with those of Grainger (2012), who also examines the effects of the 1990 CAAA on homeowners and renters separately. In Table A7 in the online appendix, we find qualitatively similar results as his using alternative instruments and different specifications, although there are minor discrepancies due to differences in sample construction.

${ }^{26}$ Similar tests for renters are provided in Table A8 in the online appendix.

${ }^{27}$ Information on home values is not available for tracts in 1980 .
} 
suggest that a one-unit drop in $\mathrm{PM}_{10}$ leads to just over $1 \%$ growth in home prices over the decade in areas close to a non-attainment monitor, and that appreciation is declining with distance.

We also consider how our restrictions on the set of monitors included in the analysis affects the main results. Results using relaxed reliability restrictions appear in Panel B of Table 5. The sample size grows by about $60 \%$ when we include monitors whose readings were flagged by the EPA as unreliable. In part because of the noisiness of these readings, the strength of our first-stage changes little despite the increase in sample size. Meanwhile, the magnitudes of the estimated impacts of reductions in $\mathrm{PM}_{10}$ on home values are very similar to the main results. A one-unit reduction in $\mathrm{PM}_{10}$ increases home values by $1-1.5 \%$ in neighborhoods within three miles of a nonattainment monitor, but by less than $1 \%$ in neighborhoods further from three miles from a nonattainment monitor.

Next, we experimented with alternative measures of non-attainment for our instrument. In particular, instead of monitor and county non-attainment as instruments, we used the difference between annual $\mathrm{PM}_{10}$ concentrations in 1991 and the actual standard as an instrument. This captures the extent to which a monitor exceeds the minimum levels, which is predictive of the magnitude of subsequent changes in pollution levels. As Panel C of Table 5 shows, the secondstage estimates of the effect of $\mathrm{PM}_{10}$ changes on house prices are slightly smaller than in our main results, but again are qualitatively similar and still statistically significant for the 1-3 mile and 3-5 mile rings. ${ }^{28}$

We also considered a variety of other robustness checks that, for the sake of space, we present in the online appendix. First, the results change little when we restrict attention to tracts whose boundaries do not change substantively between 1990 and 2000, which suggests that our estimates

\footnotetext{
${ }^{28}$ The first-stage estimates for this instrument appear in Table A9 in the online appendix.
} 
are not being driven by any errors introduced in normalizing the geography (Table A10). Similarly, if instead of using partial tracts when rings overlap, we restrict attention to whole tracts, the results are very similar (Table A11). The estimated effects also change little when we include region fixed effects, which allow for differential trends in house prices across regions (Table A12). In additional tests, we exploit information about elevation, which affects air pollution concentration, as well as distance from monitors to tract centroids; qualitatively, the results are similar in each case (Tables A13 and A14).

In principle, one could take advantage of the cutoff rule determining attainment status to conduct a regression discontinuity $(\mathrm{RD})$ analysis in which one only considers a subset of the geographic areas with pollution levels within a narrow window around the threshold. Given the limited number of areas in our final sample, though, we do not have sufficient power to limit the sample to the extent needed to conduct an RD. However, if we drop from the analysis California, which has many monitors with $\mathrm{PM}_{10}$ levels that far exceed the cutoff for non-attainment status, our results are very similar. These results appear in Table A15 in the online appendix.

Sorting - A potential concern in interpreting our estimates as the MWTP for air quality improvements and in evaluating the distributional and welfare implications of the 1990 CAAA more broadly is that households may relocate in response to changes in pollution. Households could have sorted prior to 1990, such that those with the greatest distaste for air pollution lived in the areas that were initially the cleanest, or also potentially in response to the pollution changes induced by the 1990 CAAA during the 1990s, such that those living in neighborhoods with large changes in pollution by 2000 were different than those living in the same neighborhoods in 1990 .

The descriptive statistics in Table 1 suggest that the characteristics of neighborhoods close to non-attainment monitors changed little between 1990 and 2000, consistent with relatively little 
sorting in response to 1990 CAAA-induced changes in air quality. As an additional test for whether there were systematic changes in households residing in affected neighborhoods, we estimated the effect of pollution reductions on the change in the fraction of households that moved in the past five years, population density, the number of housing units, and the fraction of housing units that are owner occupied. In each case, we instrumented changes in $\mathrm{PM}_{10}$ with our measure of monitor non-attainment. One would expect to see differential rates of neighborhood turnover in areas experiencing particularly large changes in pollution induced by the policy if there were re-sorting. One might also expect to see changes in the size of the population and housing stock in these areas.

The results of these analyses appear in Table 6 . The results suggest that areas that experience relatively large policy-induced reductions in air pollution did not see particularly large changes in turnover rates, population density, housing units, or housing tenure. ${ }^{29}$ Additionally, a test for sorting based on a correlated coefficient model provides weak evidence of diminishing marginal utility with increasing air quality and no evidence of preference-based sorting (see Table A17 in the online appendix). While not conclusive given that there may be more subtle changes that we cannot detect in our data, these results imply that the sorting and supply responses to $\mathrm{PM}_{10}$ reductions induced by the 1990 CAAA were not large.

\section{Distributional Implications of the CAAA}

Earlier work on the distributional impacts of environmental policy typically found that environmental policy is regressive, with the costs largely falling on lower income households and the benefits appropriated by higher income groups (Banzhaf 2011, Fullerton 2011, Bento 2013).

\footnotetext{
${ }^{29}$ In additional tests reported in Table A16 in the online appendix, we also find little change in the age or racial composition of affected neighborhoods.
} 
In this section, we take advantage of the IV results to explore the distribution of benefits of the CAAA across households. ${ }^{30}$

To the extent that the previous literature has examined the CAAA's distributional implications, it has largely focused on differences in impacts on renters and owners (Grainger 2012). Our results suggest that, with the exception of the 1-3 mile ring, rents were largely unaffected by changes in pollution induced by the CAAA. Given this, and that we will focus exclusively on heterogeneity in the CAAA's impacts across homeowners in what follows, we will if anything tend to understate the progressivity of the program's benefits. ${ }^{31} \mathrm{We}$ will consider welfare as measured by house price appreciation and WTP proportional to income, two commonly used measures in the literature (Fullerton 2011).

Table 7 extends the main results presented in Table 3 to assess the distribution of benefits among homeowners in treated areas. ${ }^{32}$ The first four rows provide summary information on median house values, median income, the number of owner-occupied units, and the total value of housing for each ring of the treated areas. Echoing Figure 2, both house prices and income increase as ring distance increases. MWTP for each ring is calculated using the IV estimates (as described in

\footnotetext{
${ }^{30}$ As Chay and Greenstone (2005) note, while the gradient of the hedonic price function provides the average MWTP for a one-unit decline in air pollution, the calculation of WTP requires identification of the MWTP function. An approach to obtaining this function is to make strong assumptions on its shape. Freeman (1974) showed that if preferences are homogeneous and linear with respect to air quality such that the MWTP for clean air is constant, it becomes straightforward to calculate WTP.

${ }^{31}$ The IV estimates for renters suggest that, in general, either renters do not value air quality improvements or landlords are unable to increase rents (allowing renters to appropriate most of the improvements in air quality). Therefore, renters are either unaffected by the program or have actually experienced welfare gains. The exception is the renters in the 1-3 mile ring. For these individuals, if they do not value air quality improvements, they would experience a welfare loss due to the increase in rents. On the other hand, if they value the improvements by as much as homeowners, they would have actually appropriated most of the benefits since rents increased less than housing prices.

${ }^{32}$ As Figure A4 in the online appendix shows, there is a large amount of income heterogeneity among homeowners; in fact, in 1990, one third of homeowners had household income levels below the mean household income among renters.
} 
Section V.C) and is displayed in the fifth row. ${ }^{33}$ In the sixth and seventh rows, we report per house appreciation as well as total appreciation due to air quality improvements for each ring; the latter is calculated by multiplying per house appreciation by the number of houses. The trends observed across rings for MWTP and per house appreciation reflect the results of Table 3; as distance from a monitor increases, benefits decline. On the other hand, aggregate appreciation tends to grow as distance increases. However, this is entirely driven by higher initial house values and a larger number of owner occupied units in more distant areas (see the first and second rows).

Aggregating house price appreciation across rings and also extrapolating our results to tracts around monitors not included in our sample, our results imply that the total benefits of the CAAA for the entire country was $\$ 44$ billion between 1990 and 2000. ${ }^{34}$ By comparison, Chay and Greenstone (2005) found that the improvements in air quality induced by the mid-1970s TSPs nonattainment designation under the original Clean Air Act were associated with a $\$ 45$ billion aggregate increase in housing values in non-attainment counties between 1970 and 1980.

The last row in Table 7 presents, by ring, WTP proportional to income. This number is calculated by dividing annual benefits received from the CAAA by annual income, where annual benefits equal per house appreciation due to the CAAA annualized based on a 30-year mortgage with an $8 \%$ interest rate. WTP proportional to income is largest in the $0-1$ mile ring at $1.13 \%$, and then declines gradually for the 1-3 and 3-5 mile rings. WTP proportional to income in the 5-10 mile is $0.47 \%$, less than half of what it is in the $0-1$ and $1-3$ mile rings. The benefits proportional

\footnotetext{
${ }^{33}$ We use the magnitude of the estimate for the 5-10 mile ring despite its statistical insignificance, and we set the coefficient for the 10-20 mile ring at zero due to its perverse sign.

${ }^{34}$ For homeowners in our sample alone, we estimate that the total benefit of the program amounted to $\$ 20.5$ billion between 1990 and 2000. If we assume that renters value the air quality improvements as much as homeowners, even when renters in the 1-3 mile ring pay higher rental prices, the total benefit of the program across households in our sample is $\$ 30.1$ billion. Given that our sample does not comprise the whole country, we scale up the benefits to account for the additional 26 counties designated non-attainment by the EPA, assuming households in those counties experience the same rates of capitalization.
} 
to income are zero in the largest ring. The higher values for closer rings indicate that the benefits of the pollution reductions are larger as a fraction of income for those households residing in those areas than for households living in more distant rings. Because households tend to be poorer in the close rings, these statistics point to progressivity in the distribution of benefits from the CAAA. Notably, though, while poorer households living close to monitors benefit greatly from the reductions in pollution induced by the 1990 CAAA, a larger number of households living further from monitors also benefit, but each to a smaller extent.

In order to examine how WTP proportional to income varies with income in greater detail, we move away from the ring structure and examine the relationships between pollution reductions, house price appreciation, and income levels across individual census tracts. To do so, we first project the coefficient estimates from Tables 2 and 3 to individual tracts based on the distance from each tract's centroid to the monitor. Then we calculate WTP proportional to income from the coefficient estimates and the tract-specific median family income and median house value. ${ }^{35}$

Figure 3 displays the relationship between estimated WTP proportional to income and median income. The dotted line shows the density of 1990 tract median family income across all tracts in our sample; the average median family income is around $\$ 50,000$, although as the figure makes clear, there is some right skew to the distribution. The solid line shows estimates of WTP proportional to income as a function of tract median income. WTP proportional to income is clearly declining in median income over the range of tracts where the bulk of households live (up to around $\$ 100,000)$. There appears to be some nonlinearity in WTP proportional to income above $\$ 100,000$, but there are very few households in that range. Overall, Figure 3 reinforces the results in Table 7

\footnotetext{
${ }^{35}$ This analysis contains both treated and untreated tracts within 20 miles of each monitor.
} 
showing that lower income households benefit relatively more on average from declines in pollution induced by the CAAA than higher income households.

We can further quantify the disparities in benefits illustrated in Figure 3 by comparing WTP proportional to income across quintiles of the household income distribution. Moving from poorest to richest quintile, the average WTP proportional to income is $0.30 \%, 0.21 \%, 0.15 \%, 0.14 \%$, and $0.12 \%$. In other words, the WTP proportional to income for the poorest quintile is over twice that for the richest quintile. This again suggests that, measured on a household basis, that the distribution of benefits of the CAAA were progressive.

\section{Conclusion}

Using geographically disaggregated data and exploiting an instrumental variable strategy, this paper examines the distribution of benefits associated with the 1990 Clean Air Act Amendments (CAAA). The CAAA created incentives for local regulatory officials to target the dirtiest areas for cleanup, leading to geographically uneven reductions in pollution that tended to benefit lowincome households more than high-income households. Using house price appreciation as a measure of welfare, households in the lowest quintile of the income distribution received annual benefits from the program equal to $0.30 \%$ of their income on average, over twice as much as those in the highest quintile. Our finding that the program's benefits were progressively distributed among households runs counter to conventional wisdom on the distribution of benefits from environmental regulation, which holds that such policies tend to benefit higher income households more than lower income households on average.

Our analysis focuses on the incidence of the CAAA's benefits as measured by the capitalization of air quality improvements into house values. A complete welfare analysis would 
also account for the distribution any costs of the program not captured in house prices, which past studies suggest may be regressive. Indeed, based on changes in the prices of purchased goods, Robinson (1985) finds that the costs proportional to income for pollution abatement during the 1970s were about twice as large for households in the lowest quintile of the income distribution than for households in the highest quintile. Assuming the costs of air pollution abatement were similarly distributed in the 1990 s, then given that our analysis suggests that benefits of the CAAA for households in the lowest quintile were about two times larger than those for households in the highest quintile, the total costs of the CAAA would need to exceed the benefits for the program to be regressive overall. However, the U.S. EPA (2011) estimated that the benefits far exceed the costs, possibly by a factor of as much as 30, which implies that the entire program was likely progressive.

\section{References}

Auffhammer, Maximillian, Antonio Bento, and Scott Lowe, "Measuring the Effects of the Clean Air Act Amendments on Ambient PM10 Concentrations: The Critical Importance of Spatially Disaggregated Analysis," Journal of Environmental Economics and Management 58 (2009), 15-26.

Bajari, Patrick, Jane Fruehwirth, Kyoo Il Kim, and Christopher Timmins, “A Rational Expectations Approach to Hedonic Price Regressions with Time-Varying Unobserved Product Attributes: The Price of Pollution," American Economic Review 102 (2012), 18981926.

Banzhaf, H. Spencer, “Regulatory Impact Analyses of Environmental Justice Effects,” Journal of Land Use and Environmental Law 27 (2011), 1-30.

Banzhaf, H. Spencer, and Randy Walsh, "Do People Vote with their Feet? An Empirical Test of Tiebout's Mechanism," American Economic Review 98 (2008), 843-863. 
Bayer, Patrick, Nathaniel Keohane, and Christopher Timmins, "Migration and Hedonic Valuation: The Case of Air Quality," Journal of Environmental Economics and Management 58 (2009), 1-14.

Becker, Randy, and J. Vernon Henderson, "Effects of Air Quality Regulations on Polluting Industries," Journal of Political Economy 108 (2000), 379-421.

Bento, Antonio, "Equity Impacts of Environmental Policy," Annual Review of Resource Economics 5 (2013), 181-196.

Chay, Kenneth, and Michael Greenstone, "Does Air Quality Matter? Evidence from the Housing Market," Journal of Political Economy 113 (2005), 376-424.

Dockery, Douglas, C. Arden Pope, Xiping Xu, John Spengler, James Ware, Martha Fay, Benjamin Ferris, and Frank Speizer, "An Association between Air Pollution and Mortality in Six U.S. Cities," New England Journal of Medicine 329 (1993), 1753-1759.

Freeman, A. Myrick, "On Estimating Air Pollution Control Benefits from Land Value Studies," Journal of Environmental Economics and Management 1 (1974), 74-83.

Fullerton, Don, “Six Distributional Effects of Environmental Policy,” Risk Analysis 31 (2011), 923-929.

Gamper-Rabindran, Shanti, Ralph Mastromonaco, and Christopher Timmins, "Valuing the Benefits of Superfund Site Remediation: Three Approaches to Measuring Localized Externalities,” NBER Working Paper No. 16655 (2011).

Grainger, Corbett, “The Distributional Effects of Pollution Regulations: Do Renters Fully Pay for Cleaner Air?” Journal of Public Economics 96 (2012), 840-852.

Greenstone, Michael, and Justin Gallagher, "Does Hazardous Waste Matter? Evidence from the Housing Market and the Superfund Program," Quarterly Journal of Economics 123 (2008), 951-1003.

Henderson, J. Vernon, "Effects of Air Quality Regulation," American Economic Review 86 (1996), 789-813.

Lang, Corey, "The Dynamics of House Price Capitalization and Locational Sorting: Evidence from Air Quality Changes," CES Working Paper \#12-22 (2012).

Nadeau, Louis, "EPA Effectiveness at Reducing the Duration of Plant-Level Noncompliance," Journal of Environmental Economics and Management 34 (1997), 54-78. 
National Archives and Records Administration, Federal Register, Title 42 Public Health, Chapter 85, Subchapter 1, Part D, Subpart 1, Par. 7509, United States Code of Federal Regulations (2005).

Robinson, H. David, "Who Pays for Industrial Pollution Abatement?” Review of Economics and Statistics 67 (1985), 702-706.

Rosen, Sherwin, "Hedonic Prices and Implicit Markets: Product Differentiation in Pure Competition," Journal of Political Economy 82 (1974), 34-55.

Sieg, Holger, V. Kerry Smith, H. Spencer Banzhaf, and Randy Walsh, "Estimating the General Equilibrium Benefits of Large Changes in Spatially Delineated Public Goods," International Economic Review 45 (2004), 1047-1077.

Tra, Constant, “A Discrete Choice Equilibrium Approach to Valuing Large Environmental Changes," Journal of Public Economics 94 (2010), 183-196.

U.S. Environmental Protection Agency, National Ambient Air Quality Standards (NAAQS), http://www.epa.gov/air/criteria.html. July (2005).

U.S. Environmental Protection Agency, "The Benefits and Costs of the Clean Air Act from 1990 to 2020," http://www.epa.gov/air/sect812/prospective2.html. April (2011). 
Figure 1.- $\mathrm{PM}_{10}$ Concentration Trends by Attainment Status

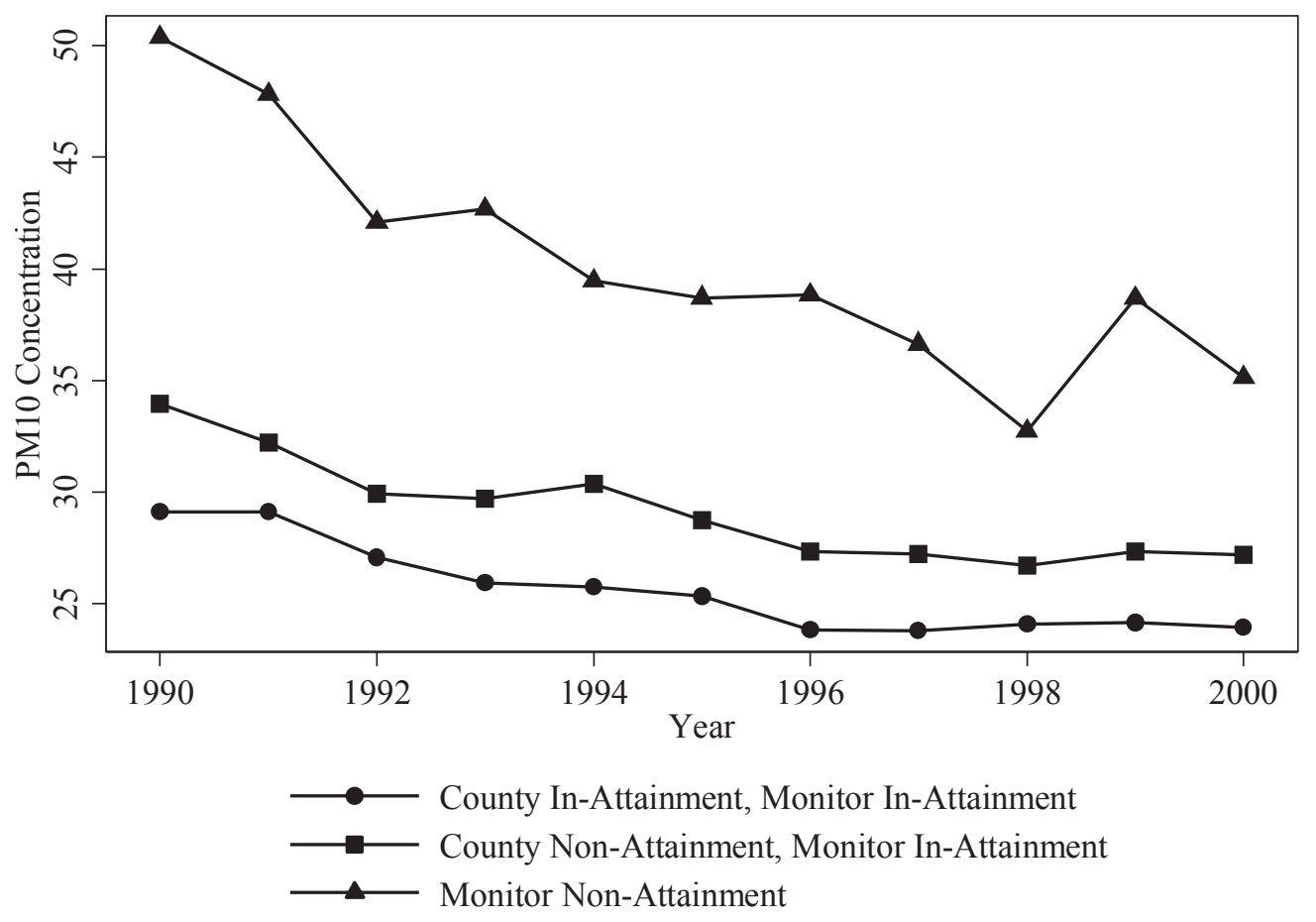

Note: The monitor sample includes all 375 monitors that are included in the analysis. A monitor is classified as 'monitor non-attainment' if it exceeds either of the EPA standards at some point during 1992-1997. A monitor is classified as 'county non-attainment' if it is located in a county that is non-attainment at some point during 1992-1997, but is not non-attainment itself. All but one monitor designated 'monitor non-attainment' are located in non-attainment counties. 


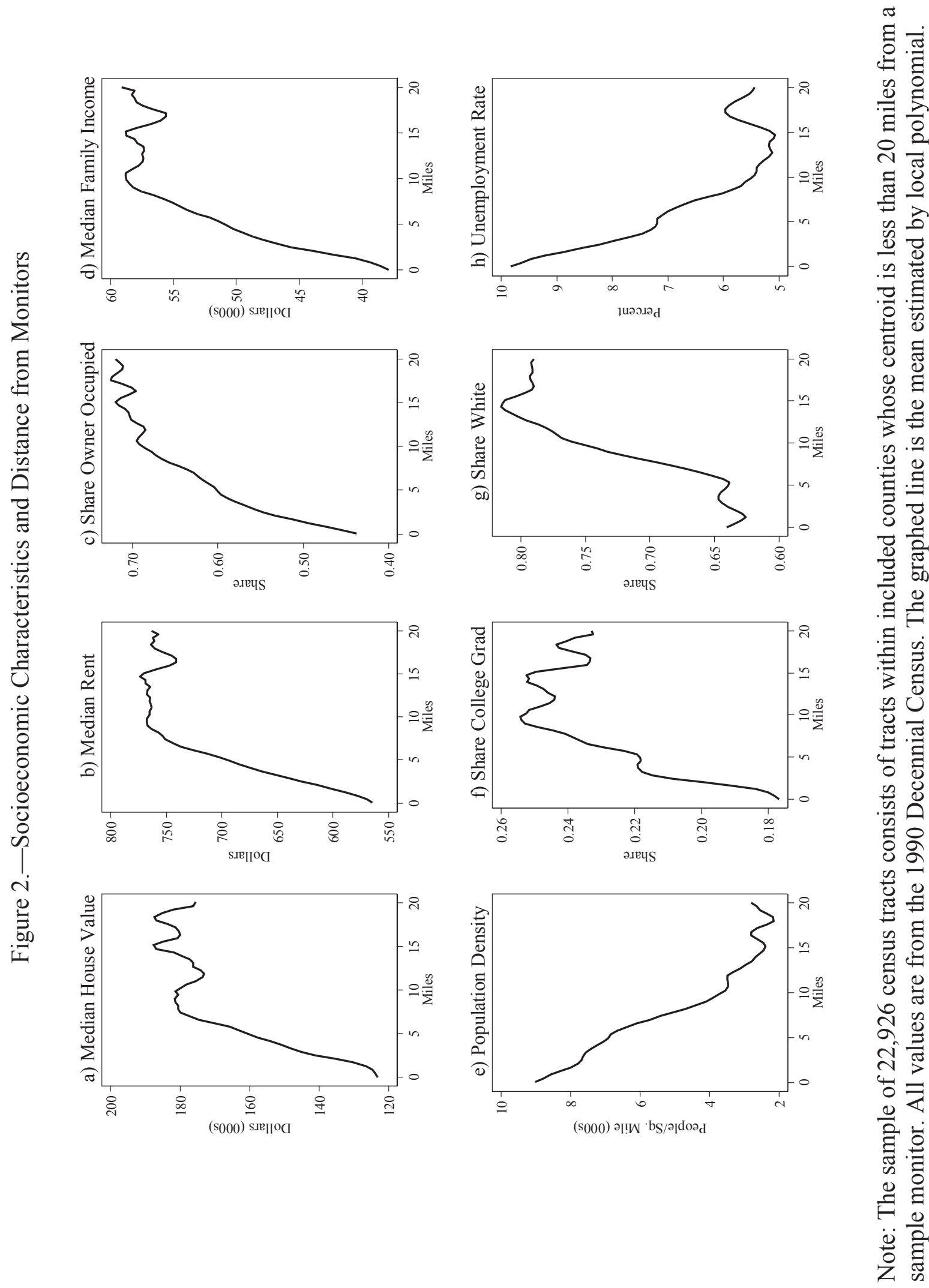


Figure 3.-Proportional WTP and Income

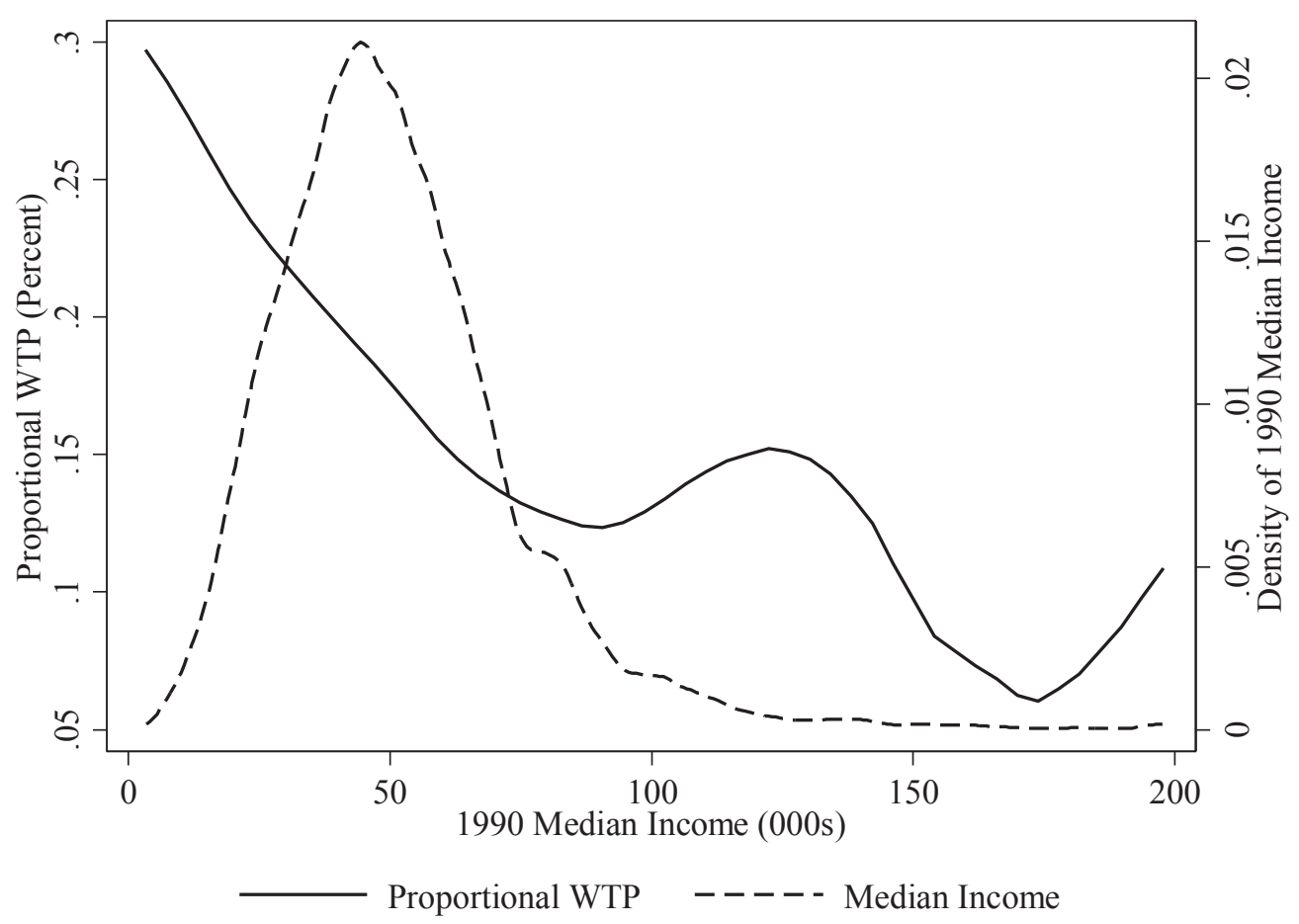

Note: The sample of 22,926 census tracts consists of tracts within included counties whose centroid is within 20 miles from a sample monitor. Proportional WTP is calculated for each tract from the first and second stage IV coefficient estimates in Table 3 and the 1990 median house price and median income of the tract. Coefficient estimates from the ring models are assigned according to the distance from each tract's centroid to the monitor. Mean proportional WTP is estimated by local polynomial. The income density is estimated by epanechnikov kernel. 


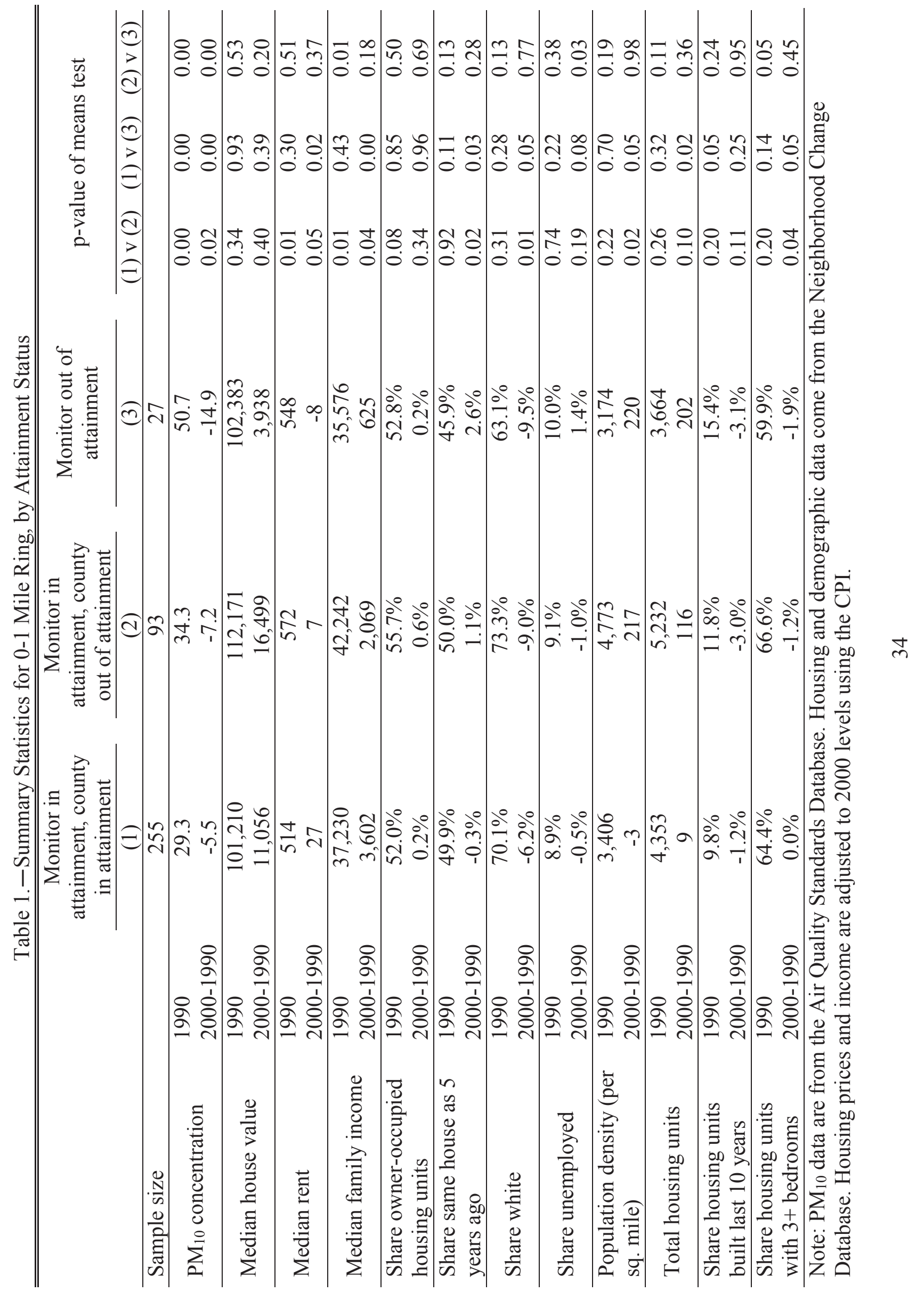


Table 2.-First Stage Results

Monitor non-attainment

(1)

(2)

$-11.85^{* * *}$

(2.71)

$-9.71 * * *$

(2.67)

County non-attainment

$-2.79 * * *$

(0.81)

F-Statistic

19.17

15.37

R-Squared

0.29

0.29

Sample size

375

375

Notes: The dependent variable is the change in $\mathrm{PM}_{10}$ concentration. Both regressions include the full set of controls listed in Table A2 in the online appendix and use the ratio instruments constructed from years 1992-97. Standard errors are shown in parentheses and are estimated using the Eicker-White formula to correct for heteroskedasticity and are clustered at the county level. *, **, and $* * *$ indicate significance at $10 \%, 5 \%$, and $1 \%$, respectively. 


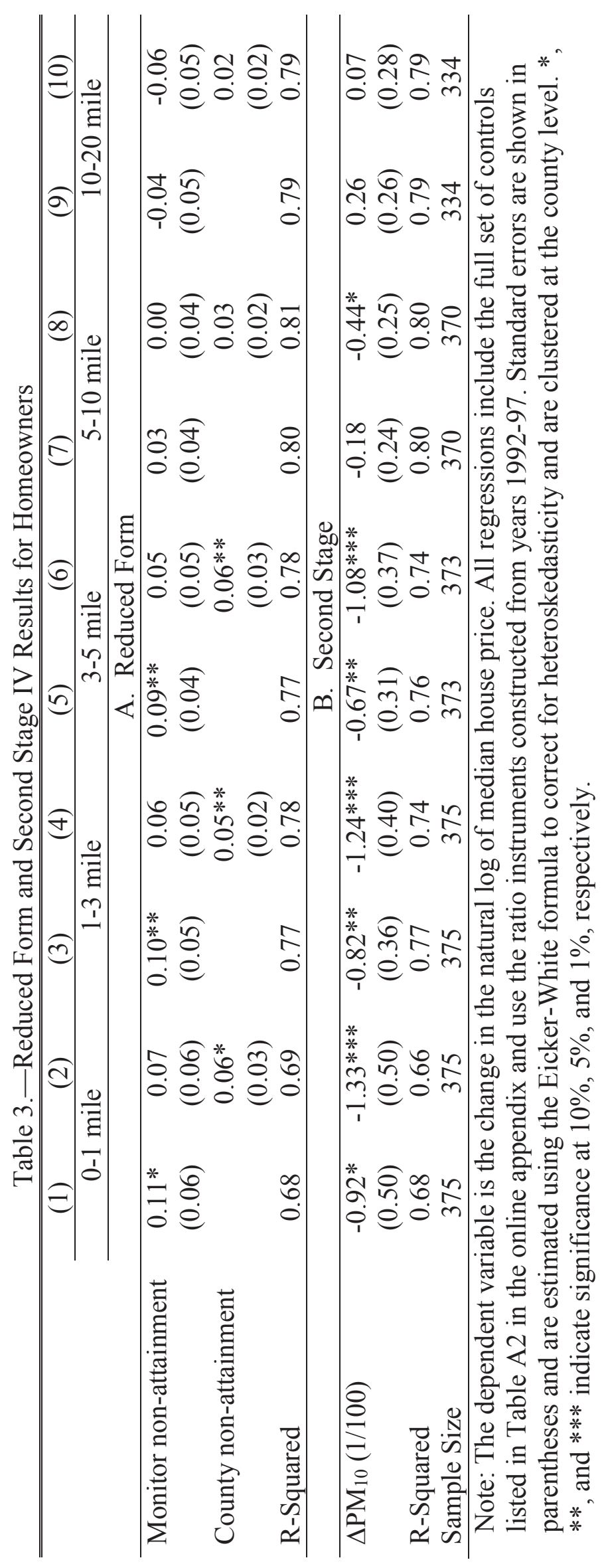




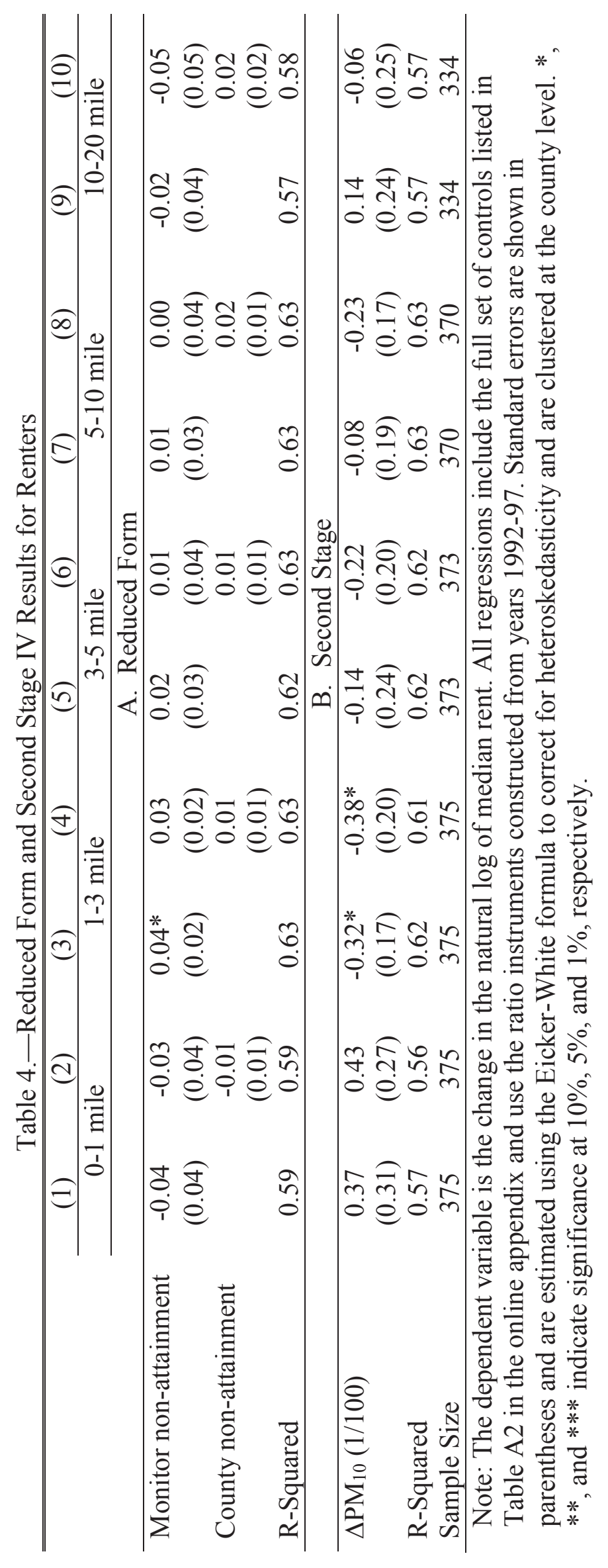

n 


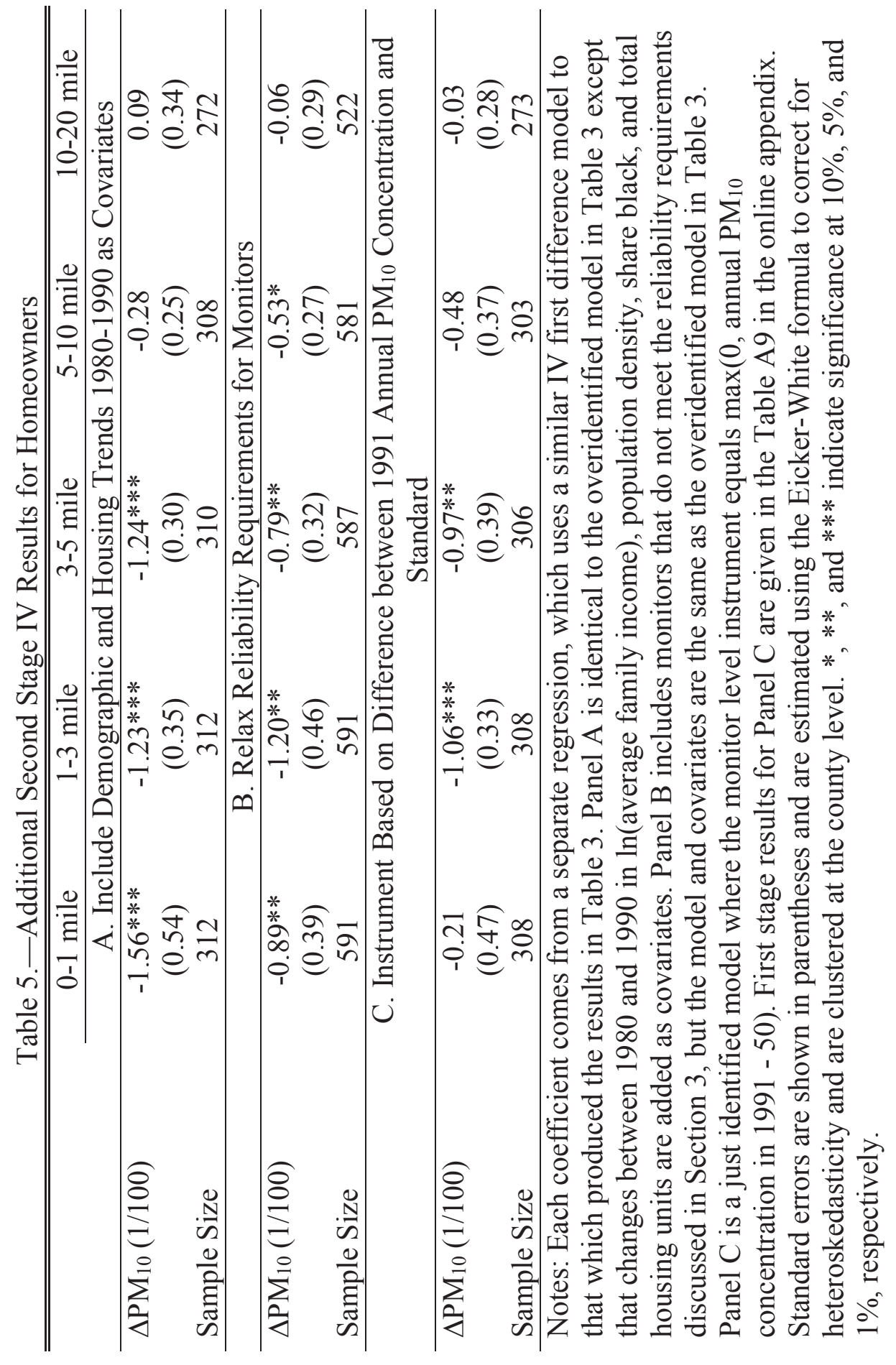




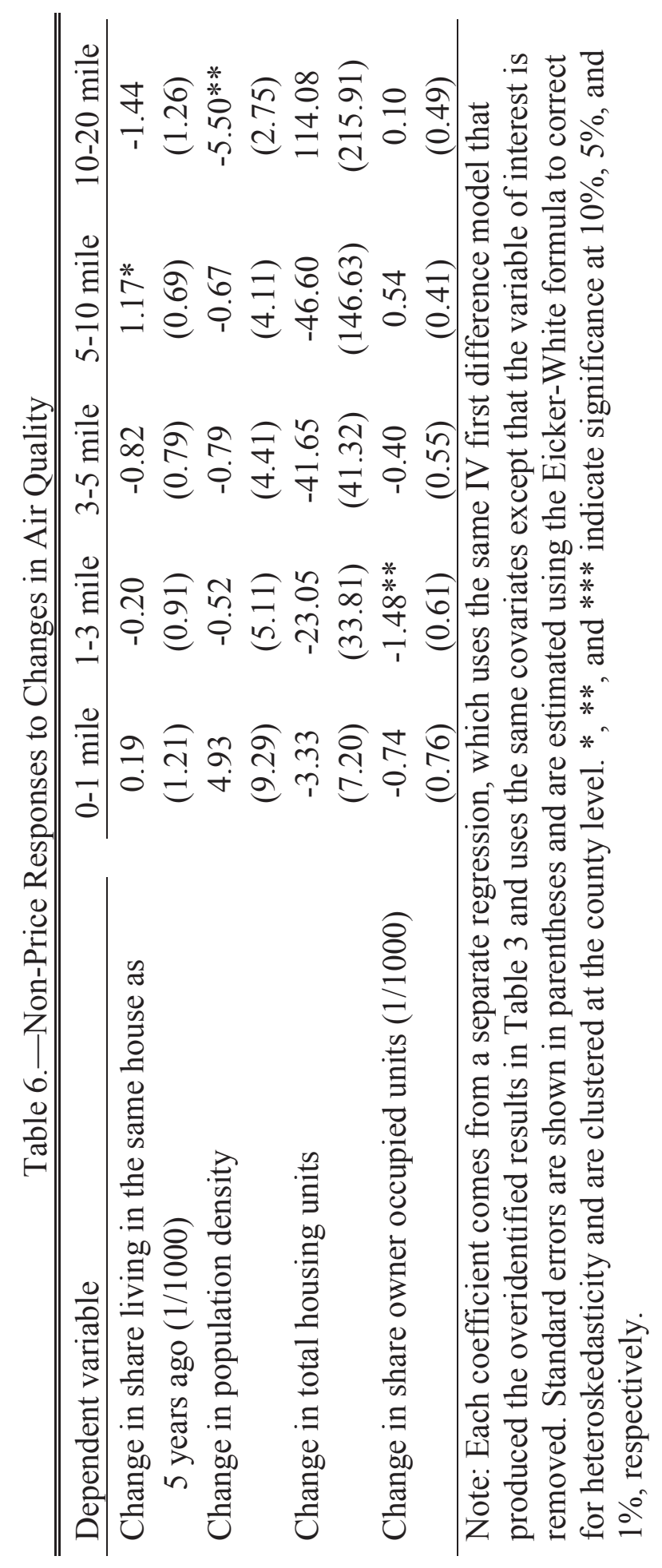




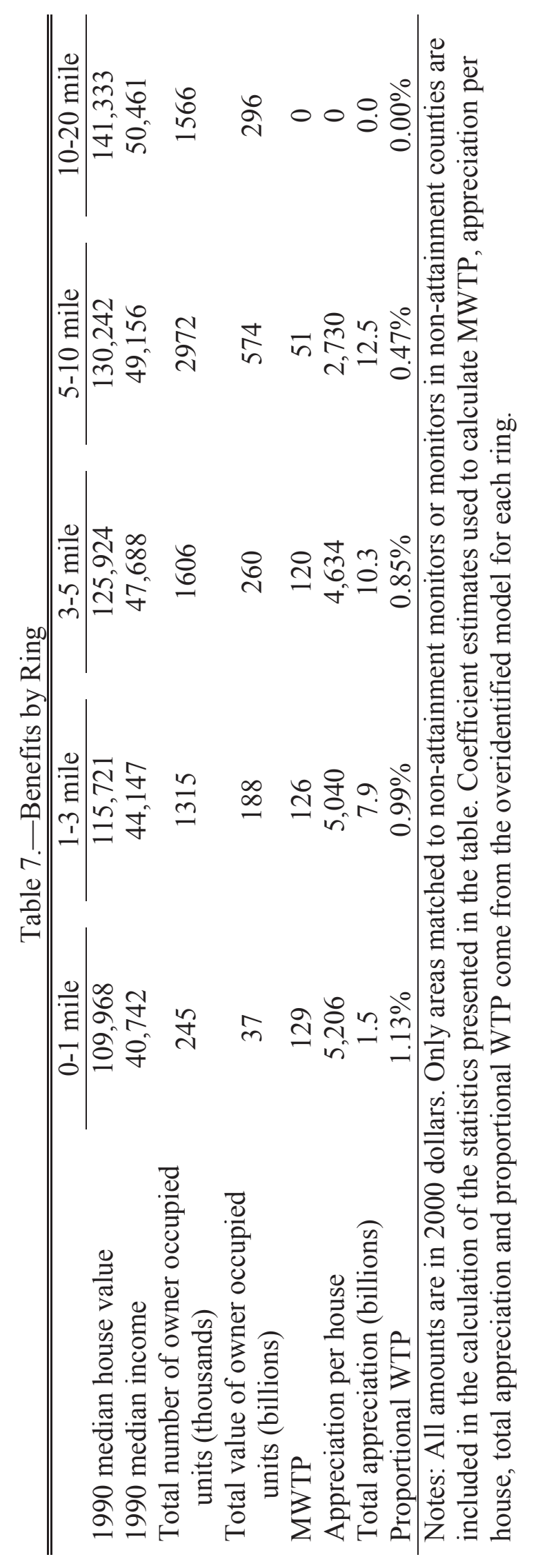

